\title{
Evaluation of Warm-Mix Asphalt Compaction Performance by Variable-Temperature Gyratory Compaction
}

\author{
Liming WANG ${ }^{1,2, a}$, Yiqiu TAN ${ }^{1, b}$ \\ ${ }^{1}$ School of Transportation Science and Engineering, Harbin Institute of Technology, Harbin 150090, \\ China \\ ${ }^{2}$ College of Civil Engineering, Northeast Forestry University, Harbin 150040,China \\ awlmdxx@126.com, byiqiutan@163.com
}

\begin{abstract}
Keywords: compactibility, optimum compaction temperature, Warm-Mix Asphalt, gyratory compaction, variable-temperature
\end{abstract}

\begin{abstract}
For dynamic changes of viscosity reducing mechanism of different types of additives in after mixing mixture, the Warm-Mix Asphalt would present different compaction performance development with the change of paving temperature and time. The authors employed an improved variable-temperature gyratory compaction experiment to evaluate different mixtures' compaction performance. In the research, specimen preparation were tried to imitate natural cooling process of paving construction, and the development of construction energy index and the optimum compaction temperature were two ways to carry out qualitative and quantitative evaluation respectively. The authors proposed an equidensity -temperature method which based on analogous principle to determine the optimum compaction temperature of Warm-Mix Asphalt indirectly, this method fit for those mixture that their optimum compaction temperature can not be predicted by binder directly, and can also avoid defects of the direct methods by mixture. According to the experiment results, there is significant difference in the compactibility and the optimum compaction temperature to different Warm-Mix Asphalt. The overall evaluation information of Warm-Mix Asphalt compaction performance could be get by the combination used of the variable-temperature gyratory compaction and the evaluation methods in the paper.
\end{abstract}

\section{Introduction}

Background and Objective. Compared with Hot-Mix Asphalt(HMA), Warm-Mix Asphalt(WMA) can be mixed at a relative lower temperature by reducing viscosity of binder or cohesive strength of aggregate surface at high temperature. The residual viscosity reducing mechanism in after mixing mixture make WMA have warm pave performance[1].

At present, there are about four typical ways to produce WMA: (1) Reducing binder's viscosity by asphalt foaming; (2)Coating emulsified asphalt on hot aggregates; (3)Adding high melting point of organic additives; (4)Diluting binders with solvent. After mixing, the residue of viscosity reducing effect in different WMA will change with paving time and temperature significantly, and thus the compaction performance of different WMA will be distinct.

The compaction performance of mixture contains two indexes: compactibility and OCT (Optimum Compaction Temperature). The compactibility presents the workability at certain temperature. The OCT presents neither slippage -upheaval nor cracking when compacted at this temperature range. Those two indexes, especially the latter, are important indicator of the construction control.

Evaluation Methods of the Compactibility By Gyratory Compaction. Compactibility evaluation is the estimate of the density growth law in compaction process. The SGC (Superpave Gyratory Compacter) collect compaction height continuously, facilitates the analysis of density-energy relationship. Compactibility evaluation by CEI (Construction Energy Index) computed base on SGC compaction curves is shown in Fig.1.

The $C E I$ is a energy index which the mixture density was compacted from certain low to high degree in the paving process[2,3]. As many specifications and guides require that the pavement should be compacted to $G_{\mathrm{mm}}=92 \sim 93 \%\left(G_{\mathrm{mm}}\right.$-Grade of Maximum Theoretical Density), the area under the compaction curve from loose (0 compaction times) to a given density represents the 
energy that the pavers and rollers woke done during the construction. This index is written as

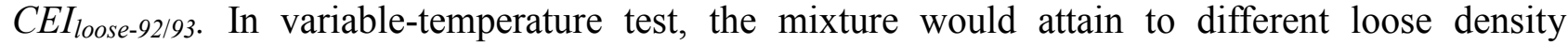
underwent 0 times compaction at different temperatures, and the value would have big random error when only compacted at static pressure. The authors employed $C E I_{88-93}$ which describes the compactibility of after initial compaction as index, it has better accuracy than $C E I_{\text {loose-92/93 }}$ in theory. The smaller the $C E I$, the easier the mixture be compacted.

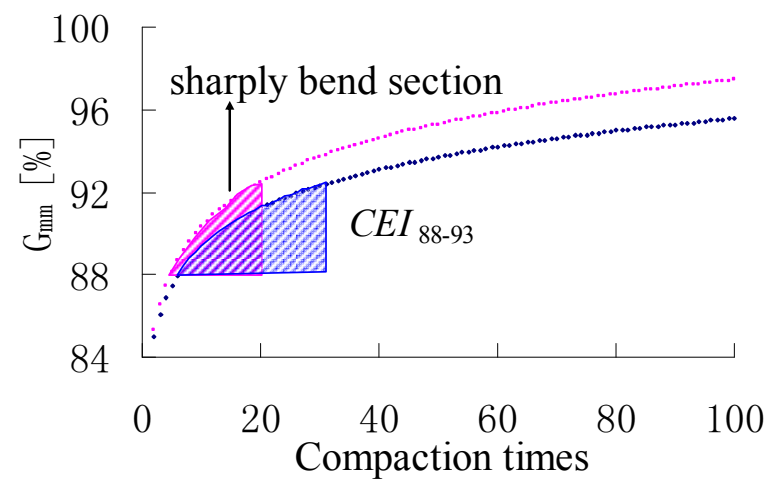

Fig. 1 The $C E I_{88-93}$ of different mixture

Determine Method of the OCT. If WMA were produced base on the mechanisms of foregoing (1), (2) and (4), the composition and effect of viscosity reducing in after mixing mixture would change dynamically, not only change with paving temperature and paving time, but also change with the mixing temperature and mixing time. Those WMA OCT can't be determined directly with binder's equiviscosity-temperature method according to the ASTM D2493. If WMA was produced base on the mechanism of foregoing (3), there are also research showed that the OCT which estimated by asphalt directly would have not matched the actual project performance[4]. At the same time, the equiviscosity-temperature method would not applicable to WMA with polymer modified asphalt. For above reasons, The OCT of WMA should be determined through the mixture.

At present, the OCT determined direct method though variable-temperature compaction is commonly used. If use unmodified asphalt, test would set a target density like in reference [5], and then to find OCT in compaction curves. If polymer modified asphalt was used, similar to the reference [6], there might be a density peak at high temperature stages, and could be used as density standard of the OCT. Whichever direct methods are used, there are four defects: (1)Different compaction methods or mixture types have different target densities, assumed standard is difficult to determine; (2)Even if modified asphalt had been used, the density peak is almost impossible appear under WMA mixing temperature; (3)Some asphalt's viscosity is sensitive to shear rate, when compaction shear rate different from laboratory to in site roller work, directly determined OCT may not be suitable for the construction; (4)The final density of standard compaction will not sensitive to temperature change if the compaction energy is too large or the compaction temperature is too high.

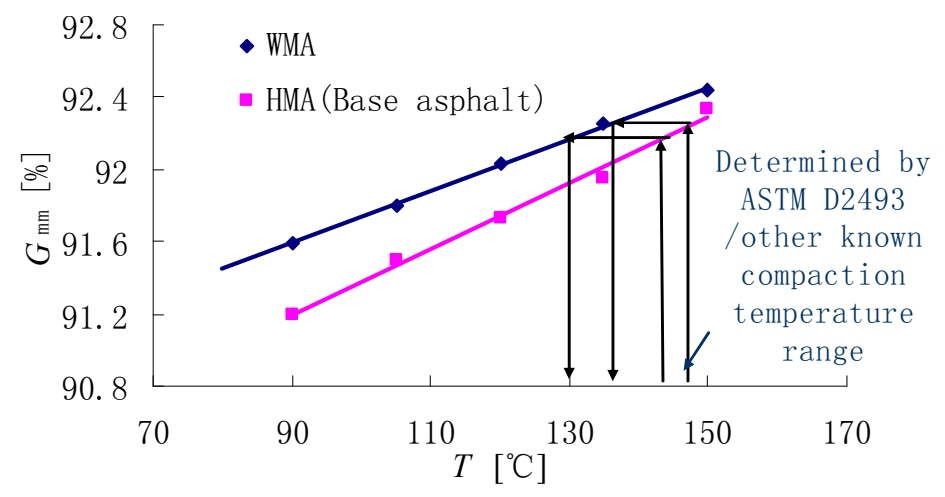

Fig.2 Theoretical process of the equidensity-temperature method

From above analysis, it is an ideal method that analogy is employed to avoid first three defects in the above paragraph. This method compares variable-temperature compaction density-temperature curves of WMA with others which its/their compaction temperature have been known. This method is called equidensity-temperature method, its theoretical process shown in Fig.2. In the paper, basic 
HMA with unmodified asphalt was used as an analog object, the OCT of HMA was determined by ASTM D2493 which employed Brookfield viscometer. In the process of analogy, the density in energy sensitive areas in compaction curves was chosen as the analogy index.

\section{Experimental Design of Variable-Temperature Gyratory Compaction}

Basic Mixture. As experiment mixture should reflect the effect of asphalt film on shearing process of compaction as far as possible, a soft and fine dense-graded HMA was chosen as the basic mix proportion deliberately. Its optimum asphalt content is $4.5 \%$, and the gradation distribution is listed in Table 1.

Table 1 Gradation distribution of basic dense-graded HMA

\begin{tabular}{ccccccccccc}
\hline Mesh size [mm] & 0.075 & 0.15 & 0.3 & 0.6 & 1.18 & 2.36 & 4.75 & 9.5 & 13.2 & 16 \\
\hline Passrate [\%] & 6 & 9 & 13 & 19 & 18 & 41 & 59 & 80 & 93 & 100 \\
\hline
\end{tabular}

Performance parameters of the base asphalt used for test are listed in Table 2.

Table 2 Performance parameters of asphalt

\begin{tabular}{ccccc}
\hline $\begin{array}{c}\text { Penetration } \\
{\left[25^{\circ} \mathrm{C}, 0.01 \mathrm{~mm}\right]}\end{array}$ & $\begin{array}{c}\text { Softening point } \\
{\left[{ }^{\circ} \mathrm{C}\right]}\end{array}$ & $\begin{array}{c}\text { Ductility } \\
{[\mathrm{cm}]}\end{array}$ & Penetration index & $\begin{array}{c}\text { Compaction temperature } \\
{\left[{ }^{\circ} \mathrm{C}\right]}\end{array}$ \\
\hline 81 & 42.7 & 153 & -1.5 & $134 \sim 138$ \\
\hline
\end{tabular}

Notes: JTG E20-2011 test standard

In the experiment, the authors prepare a basic HMA and four kinds of WMA, different WMA use different additives, and Table 3 is the description of the additives .

Table 3 Description of the test additives

\begin{tabular}{clll}
\hline Name & \multicolumn{1}{c}{ Basic chemical composition } & \multicolumn{1}{c}{ Dosage } & \multicolumn{1}{c}{ Usage } \\
\hline A & synthetic zeolite powder with crystal water & $0.3 \%$ (mixture) & add in with filler \\
B & dilute emulsifier with water & $10 \%$ (binder) & add in the asphalt just before mix \\
C & high melting point paraffin wax & $3.5 \%$ (binder) & add in the asphalt in advance \\
D & composite liquid organic solvent & $3.5 \%$ (binder) & add in the asphalt just before mix \\
\hline
\end{tabular}

Those WMA with different additives are called WMA(A),WMA(B),WMA(C) and WMA(D) respectively. Because of the small additives residual dose in after mixed mixture, the mix proportion need not to be changed.

Specimen Preparation Process. In order to unify test condition, All WMA were mixed at $145^{\circ} \mathrm{C}$ uniformly according to the instructions of additives' producer, whiles the HMA was mixed at $155^{\circ} \mathrm{C}$. Some WMA, such as those production mechanism are based on the foaming, emulsification and dilution, are not suitable for controlling the temperature slowly in the oven. In the research, mixtures temperature had been controlled after placed into molds. The detailed specimen preparation method is a three-steps process: first, the after mixing mixtures were weighed accurately and placed into mold with heat preservation cover as quick as possible, second, pre-compacted to $G_{\mathrm{mm}} \approx 80 \%$ by static pressure, at last, specimens were gradually cooled to test temperature at room temperature similar to paving process. The process of specimen preparation is shown in Fig 3.

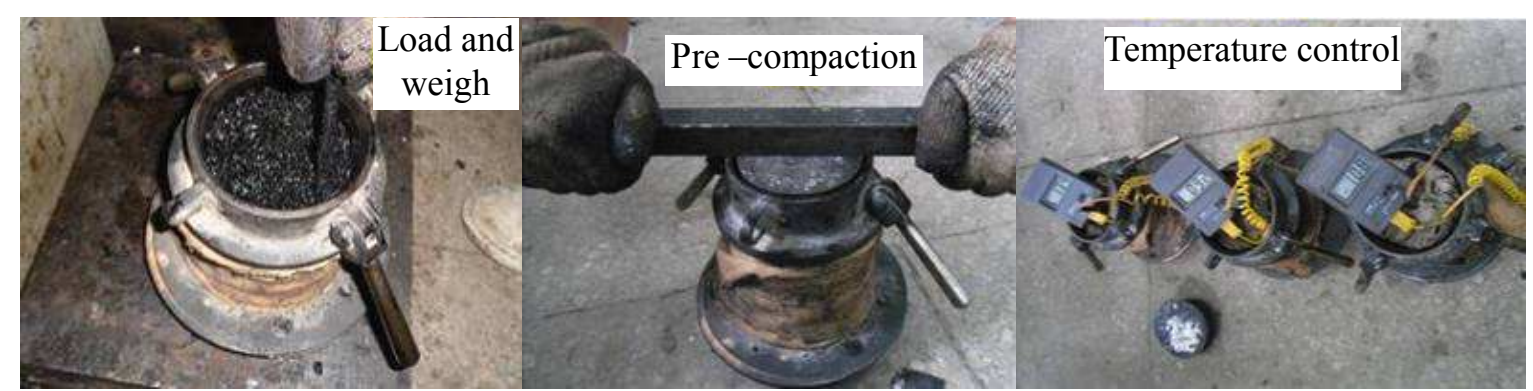

Fig.3 The process of specimen preparation

Compaction Conditions Control. The study use an old standard SGC, its rotation angle is $1.25^{\circ}$, compaction load is $600 \mathrm{kPa}$. The compaction temperature from $135^{\circ} \mathrm{C}$ to $90^{\circ} \mathrm{C}$ interval $15^{\circ} \mathrm{C}$. At every temperature, one experiment set was conducted and each set has twice parallel test, the basic HMA was added a set at $150^{\circ} \mathrm{C}$. 


\section{Results and Discussion}

According to the experimental conditions control of above, the authors get five set of different whole process compaction curves, all of them were plotted in Fig.4.
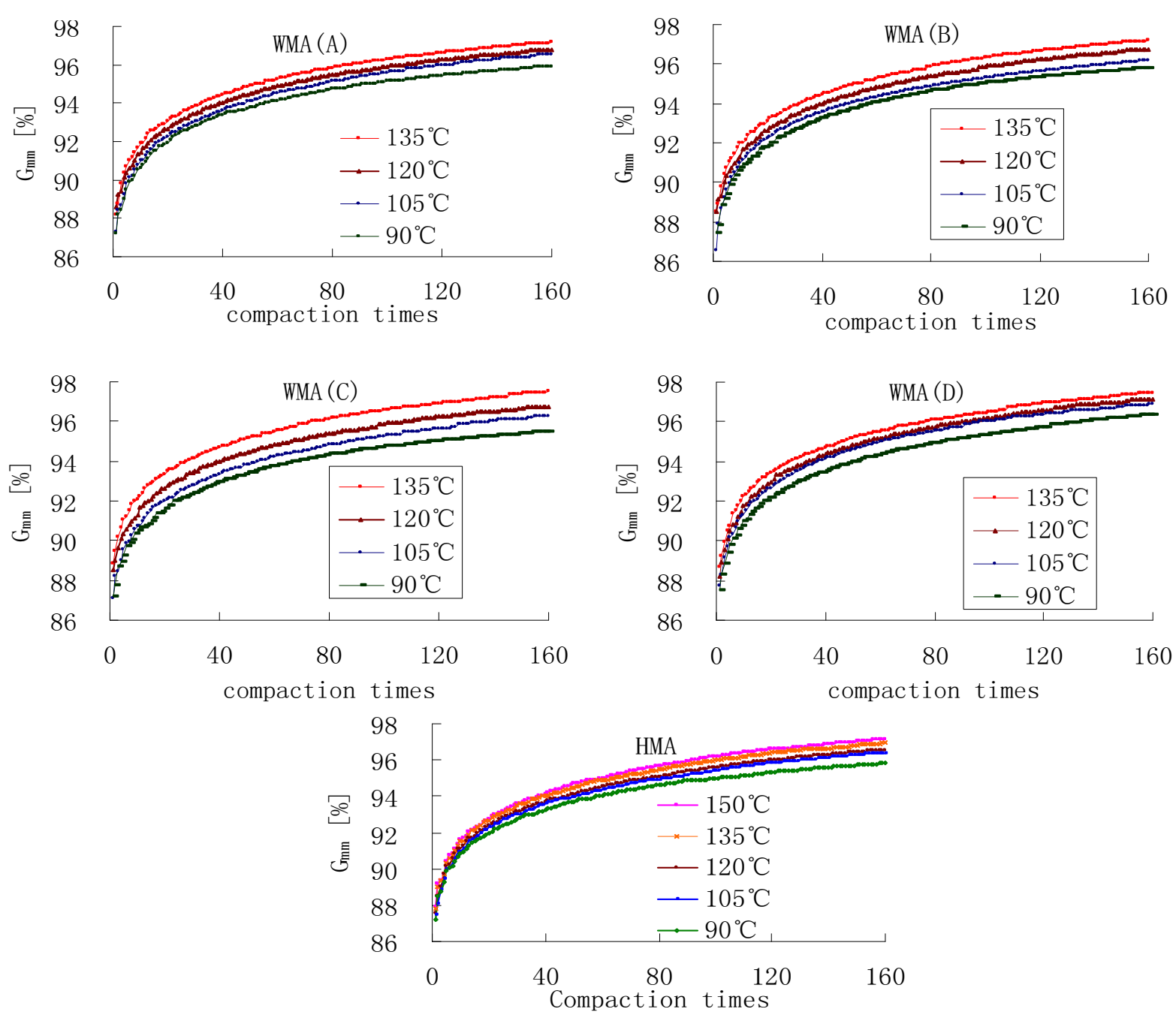

Fig.4 Compaction curves of variable-temperature experiment

Compactibility Evaluation of WMA. According to evaluation index described in Fig.1, the $C E I_{88-93}$ of different WMA at different temperatures were computed and plotted in Fig.5.

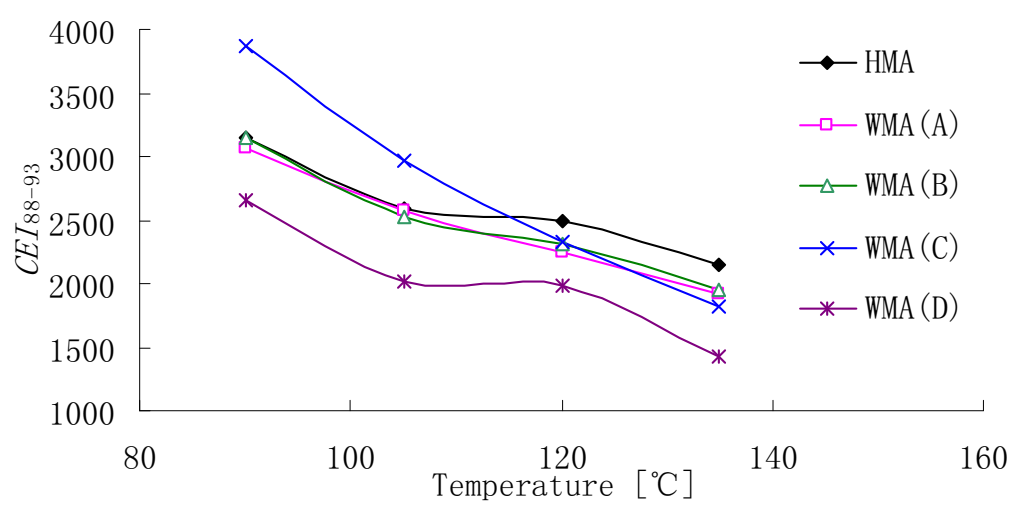

Fig. $5 C E I_{88-93}$ of different WMA at different temperatures

In the Fig.5, the $C E I_{88-93}$ of all types of WMA obvious lower than that of the HMA at $135^{\circ} \mathrm{C}$, this indicates that all types of WMA have warm-pave performance. But, when the variation of the $C E I_{88-93}$ are concerned, different WMA presents different development trends. WMA (A) and WMA (B) shows similar trends, their $C E I_{88-93}$ lower than that of the HMA over $105^{\circ} \mathrm{C}$, it means that 
those two WMA easy to compact over the temperature, while with the temperature decreases, this effect fades away and the compactibility approach to HMA under $105^{\circ}$ Cgradually. WMA (C) significantly reduce the compaction power at $135^{\circ} \mathrm{C}$, but if the compaction temperature decreases to under $105^{\circ} \mathrm{C}$, the $C E I_{88-93}$ would higher than HMA. This appearance might be related to the about $100^{\circ} \mathrm{C}$ melting point of the additives, when the temperature is lower than $100^{\circ} \mathrm{C}$, hardening additives no longer has help effect to compaction, but increases compaction difficult. At any compaction temperature, the $C E I_{88-93}$ of WMA (D) is the smallest, and its development trend like that of the HMA. This low shows that WMA (D) has the best warm-pave performance.

When $C E I_{88-93}$ at $135^{\circ} \mathrm{C}$ (conventional paving temperature) is used as apples-to-apples evaluation criteria, the order of different mixtures' compactibility is WMA(D) $>$ WMA(C) $>$ WMA (B) $\approx$ WMA $(\mathrm{A})>$ HMA.

The OCT of WMA. All $G_{\mathrm{mm}}$ of a certain compaction times in Fig.4 were collected and paired plotted in Fig. 6 accordance with the manner of Fig.2. The certain compaction times should lies in the certain curve range that its $G_{\mathrm{mm}}$ has clear difference and sensitive to compaction temperature, this range is the sharply bend section of a compaction curve. In the paper, 30 times were selected.
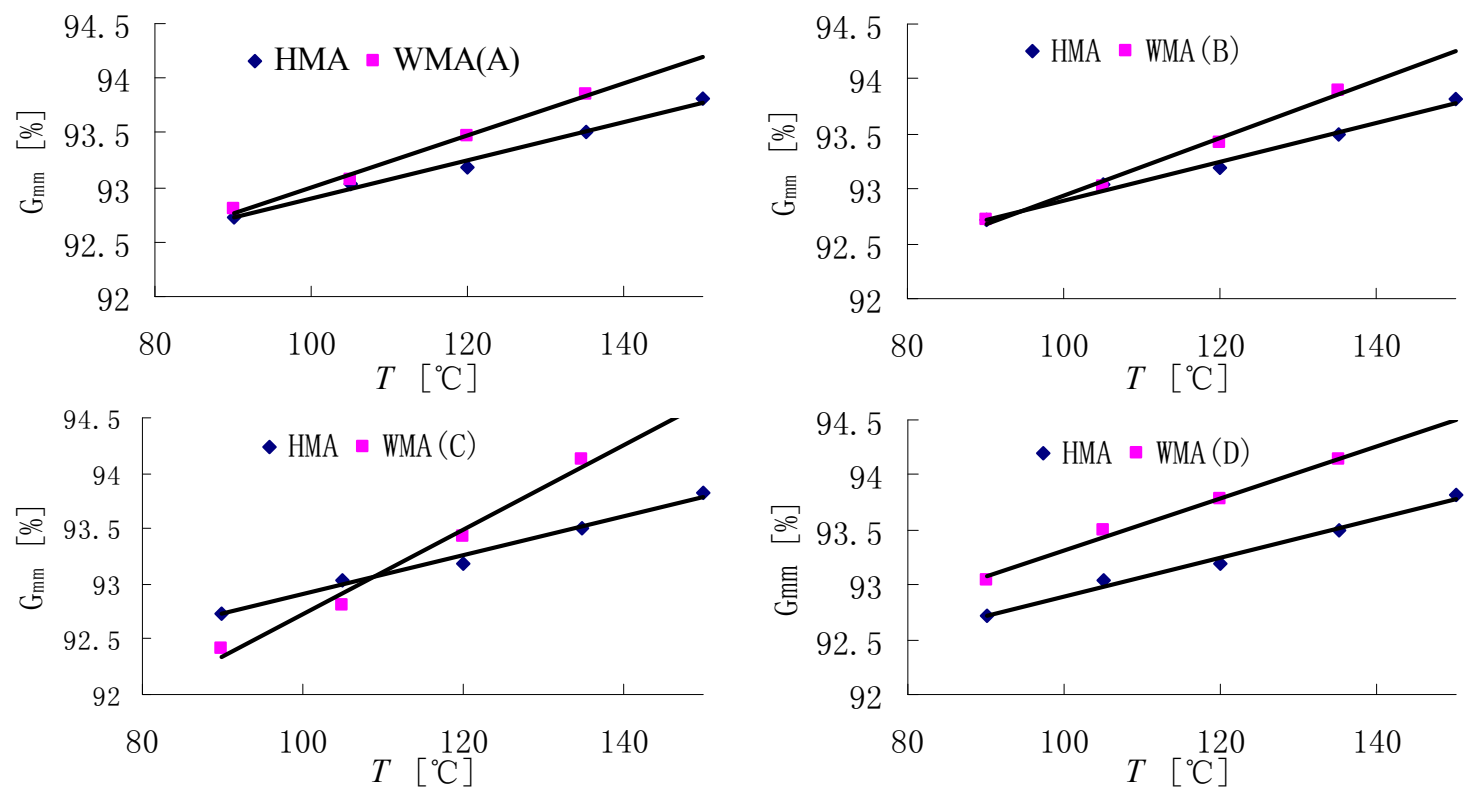

Fig.6 Temperature-density paired drawings of 30 compaction times

According to the equidensity-temperature method in Fig.2, the OCT of different WMA were determined and listed in Table 4.

Table 4 OCT of different WMA

\begin{tabular}{cc|cc}
\hline Mix type & OCT $\left[{ }^{\circ} \mathrm{C}\right]$ & Mix type & OCT $\left[{ }^{\circ} \mathrm{C}\right]$ \\
\hline WMA(A) & $121 \sim 124$ & WMA(B) & $122 \sim 124$ \\
WMA(C) & $121 \sim 123$ & WMA(D) & $108 \sim 111$ \\
\hline
\end{tabular}

Compared with HMA, the OCT reduction of WMA(A),WMA(B) and WMA(C) in Table.4 are close, it is about $12 \sim 15^{\circ} \mathrm{C}$, while the reduction of WMA(D) reaches to $26 \sim 27^{\circ} \mathrm{C}$. Above data are far less than advertise of additives producers, the reason is that producer' data are commonly compared with the limit of actual construction. In addition, due to the difference of additives' property, additives' dose, binder's property and test condition control which used in different research, the absolute reduction of WMA compaction temperature is difficult to quantify.

OCT ranges of all WMA in Table.4 look narrower than that of the basic HMA, In fact, it's the result that limited number of data is fitted to straight line. If small steps were used in variable-temperature test, the experimenter can get a high related coefficient fitted curve which their middle section may flatter than HMA, then a wider range might be get. Nevertheless, if parameter level is less, the linear fitting should be priority.

Overall Evaluation of Different WMA Compaction Performance. Compared with the basic HMA, the compactibility and the OCT reduction of WMA(A) and WMA(B) are similar, with the cooling of mixtures, two additives effect to compaction performance gradually reduced and closer 
to disappear. The $\mathrm{WMA}(\mathrm{C})$ has similar OCT reduction to $\mathrm{WMA}(\mathrm{A})$ and $\mathrm{WMA}(\mathrm{B})$ at high temperature, while its compactibility obvious lower than that of the first two under $105^{\circ} \mathrm{C}$. The compactibility of WMA(D) significantly higher than others, and its OCT reduction reaches to $26 \sim 27^{\circ} \mathrm{C}$. Such compaction performance as WMA(D) is beneficial to extending the effective compaction time under low temperature, but may affect the opening time to traffic and the early high temperature stability, in other words, WMA(D) is not Warm-Mix Asphalt to a certain extent.

\section{Conclusion}

$i$.For dynamic changes of viscosity reducing mechanism of WMA additives in after mixing mixture, the condition control of variable-temperature gyratory compaction experiment needs to be improved. The specimen preparation method in the paper make its cooling process approach to actual construction condition.

ii . The analysis of $C E I_{88-93}$ based on variable-temperature gyratory compaction experiment can qualitative evaluate WMA's compactibility and their development with the temperature change. At $135^{\circ} \mathrm{C}$, the order of different mixtures' compactibility is WMA (D) $>$ WMA(C) $>$ WMA (B) $\approx$ WMA $(\mathrm{A})>\mathrm{HMA}$, while with the decrease of compaction temperature, different types of WMA shows a distinct difference. The compactibility of WMA (A) and WMA(B) gradually reduced and closer to disappear when temperature decreases. The compactibility of WMA (C) lower than that of the basic HMA under $105^{\circ} \mathrm{C}$. At any compaction temperature, the $C E I_{88-93}$ of WMA (D) is the smallest and its compactibility higher than any mixture consistently.

iii. The equidensity-temperature method is an indirect way based on analogous principle to determine the OCT of asphalt mixture that unsuited to be predicted by binder directly, and can also effectively avoid defects of the direct methods by mixture. By means of the equidensity-temperature method, the OCT reduction of $\mathrm{WMA}(\mathrm{A}), \mathrm{WMA}(\mathrm{B})$ and $\mathrm{WMA}(\mathrm{C})$ are similar and about $12 \sim 15^{\circ} \mathrm{C}$, while the reduction of $\mathrm{WMA}(\mathrm{D})$ reaches to $26 \sim 27^{\circ} \mathrm{C}$.

iv. The overall evaluation information of Warm-Mix Asphalt compaction performance could be get by the combination used of the variable-temperature gyratory compaction and the evaluation methods in the paper.But, as dynamic residual of viscosity reducing mechanism of most of WMA additives, not only relate to the compaction temperature and time, but also relate to the mixing temperature, the condition control of variable-temperature experiment has great effect on experimental results. Therefore, to those kinds of mix, the evaluation of compaction performance is relative rather than absolute.

\section{References}

[1]ZHANG Zhen,SUN Li-jun. The Control Indicates Research of Evotherm Warm-Mix Asphalt, J. Journal of Wuhan University of Technology. 2009,31(8) 29-32

[2]ZHANG Zheng-qi,YUAN Ying-jie,WANG Bing-Gang. Information of Gyratory Compaction Densification Curve of Asphalt Mixture and Its Application, J. China Journal of Highway and T ransport. .2005,18 (3) :1-6

[3]LI Yu-shi,YANG Rui-hua,SHAO la-geng,LI Chuang-min. Compactness Analysis of Asphalt Mixture, J. Journal of Highway and Transportation research and Development. 2005,22 (3) 28-34

[4]ZHOU Yan,CHEN Suan-fa,ZHENG Mu lian ZHANG kai. Research on Mixing and Compaction Property of Warm Mix Asphalt., J. Journal of Wuhan University of Technology. 2010,32(1)61-64

[5]WU Chao-fan,ZENG Meng-lan, WANG Mao-wen,XIA Yang. Determination of the Mixing and Compaction Temperatures for Warm Mix Asphalt with Sasobit, J. Journal of Hunan University(Natural Sciences), $2010,37(8)$ 1-5

[6]LI Ning-li, LI Tie-hu, CHEN Hua-xin,ZHANG Zheng-qi. Mixing and Compaction Temperatures of Modified Asphalt Mixture, J. China Journal of Highway And Transportation , 2007, 20(2)40-44 